\author{
Sophia Haussener \\ Department of Mechanical and Process \\ Engineering, \\ ETH Zurich, \\ 8092 Zurich, Switzerland \\ Wojciech Lipiński \\ Department of Mechanical Engineering, \\ University of Minnesota, \\ Minneapolis, MN 55455 \\ Peter Wyss \\ Department of Electronics/Metrology, \\ EMPA Material Science and Technology, \\ Überlandstrasse 129, \\ 8600 Dübendorf, Switzerland \\ Aldo Steinfeld ${ }^{1}$ \\ Department of Mechanical and Process \\ Engineering, \\ ETH Zurich, \\ 8092 Zurich, Switzerland \\ and \\ Solar Technology Laboratory, \\ Paul Scherrer Institute, \\ 5232 Villigen, Switzerland \\ e-mail: aldo.steinfeld@ethz.ch
}

\section{Tomography-Based Analysis of Radiative Transfer in Reacting Packed Beds Undergoing a Solid-Gas Thermochemical Transformation}

A reacting packed-bed undergoing a high-temperature thermochemical solid-gas transformation is considered. The steam-and dry-gasification of carbonaceous materials to syngas is selected as the model reaction. The exact $3 D$ digital geometrical representation of the packed-bed is obtained by computer tomography and used in direct pore-level simulations to characterize its morphological and radiative transport properties as a function of the reaction extent. Two-point correlation functions and mathematical morphology operations are applied to calculate porosities, specific surfaces, particle-size distributions, and representative elementary volumes. The collision-based Monte Carlo method is applied to determine the probability distribution of attenuation path length and direction of incidence at the solid-fluid boundary, which are linked to the extinction coefficient, scattering phase function, and scattering albedo. These effective properties can be then incorporated in continuum models of the reacting packed-bed.

[DOI: $10.1115 / 1.4000749$ ]

Keywords: packed-bed, radiation, solar energy, gasification, chemical reactors

\section{Introduction}

Morphological and effective heat/mass transfer properties of complex porous media are needed for the engineering design, optimization, and scale-up of thermochemical reactors and processes in particular for packed beds. Their complex solid-gas structures can be incorporated in direct pore-level simulations for determining their morphological-dependent effective transport properties for continuum domain. This approach has been successfully applied for the geometrical characterization of packed beds and foams [1-5] and for the determination of the effective radiative heat transfer properties of opaque and semitransparent packed beds $[3,6-8]$ and foams $[5,9,10]$, of the effective conductivity of packed beds and foams [11-14], of convective heat transfer properties $[13,15]$, and of the effective fluid flow properties $[15,16]$ through foams. These pore-level computations allow for more indepth investigations vis-à-vis classical empirical models for radiative $[17,18]$, conductive [19], convective [20], and fluid flow $[19,21,22]$ properties.

In this study, computer tomography (CT) is employed to obtain the exact $3 \mathrm{D}$ digital geometrical representation of a packed-bed of carbonaceous materials undergoing high-temperature gasification. Thus, the numerically calculated effective properties are based on the exact morphology of the reacting packed-bed, which varies with time and process parameters (e.g., temperature, gasifying agent, partial pressure, and feedstock size) as the reaction progresses. These effective properties can then be applied for the

\footnotetext{
${ }^{1}$ Corresponding author.

Contributed by the Heat Transfer Division of ASME for publication in the JouRNAL OF HeAT Transfer. Manuscript received May 15, 2009; final manuscript received October 22, 2009; published online March 25, 2010. Assoc. Editor: Walter W. Yuen.
}

accurate derivation of the reaction kinetics and for the design and optimization of packed-bed reactors.

\section{Gasification Experiments}

A packed-bed of tire shreds is selected as the model reactor. The gasification of this waste carbonaceous material into highquality synthesis gas (syngas, mainly $\mathrm{H}_{2}$ and $\mathrm{CO}$, used for power generation in efficient combined-cycles and fuel cells or further processed to Fischer-Tropsch liquid fuels) is investigated in a packed-bed reactor using concentrated solar energy as the source of high-temperature process heat [23]. In this study, a laboratory packed-bed reactor, schematically shown in Fig. 1, is used to conduct the gasification reaction at controlled conditions and to produce sample materials at different reaction extents. These samples are then scanned by tomography. Their BET specific surface area is measured by $\mathrm{N}_{2}$ adsorption (Micromeritics TriStar 3000) and their particle-size distribution is measured by laser scattering (HORIBA LA-950 analyzer). Outlet gas composition is monitored by mass spectrometry (MS, Pfeiffer Vacuum OmniStar GSD 301 O1) and gas chromatography (GC, Varian CP-4900 Micro GC).

Proximity analysis of the tire shreds indicates $63 \mathrm{wt} \%$ volatiles, $29 \mathrm{wt} \%$ fixed carbon, $7 \mathrm{wt} \%$ ash and $1 \mathrm{wt} \%$ moisture. Elemental analysis indicates 82 wt $\% \mathrm{C}, 7$ wt $\% \mathrm{H}, 3$ wt \% O, 2 wt $\% \mathrm{~S}$, and heavy metal impurities. Energy dispersive X-ray spectrometer analysis shows that the main components in the ash are $\mathrm{Si}, \mathrm{Zn}$, and $\mathrm{Fe}$ based oxides. Samples are first pyrolyzed to release volatiles. Approximately $3 \mathrm{~g}$ of pyrolyzed material is loaded in a $2.6 \mathrm{~cm}$ inside diameter quartz tube, rapidly heated by a radiative source, and gasified either by steam or $\mathrm{CO}_{2}$ diluted by Ar. Once the reaction reaches a desired carbon conversion, the quartz tube is removed from the furnace and rapidly cooled. The partially reacted sample is extracted. The carbon conversion (or reaction extent) is defined by 


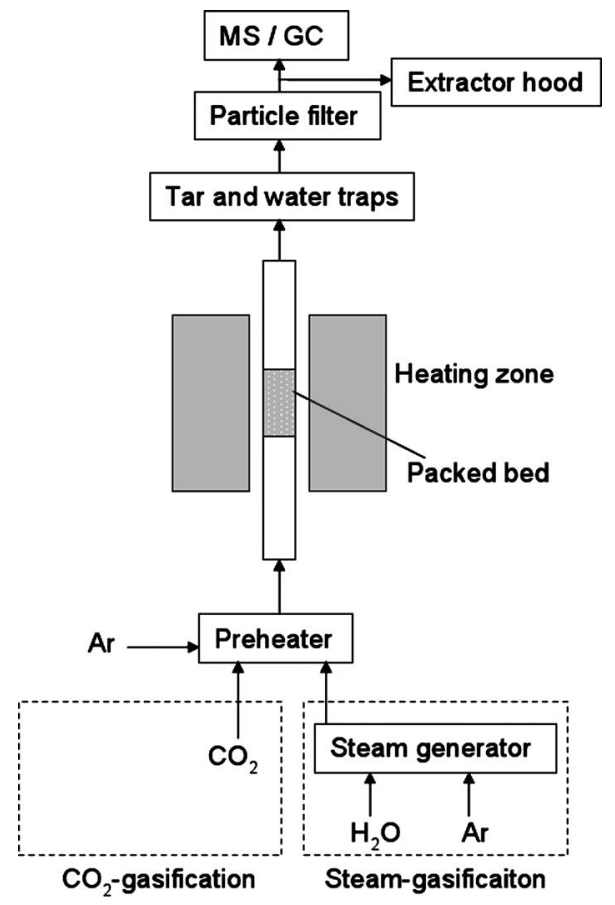

Fig. 1 Schematic of the tubular packed-bed reactor setup used for the gasification of carbonaceous materials

$$
X_{\mathrm{C}}=1-\frac{n_{\mathrm{C}}}{n_{\mathrm{C}, 0}}=\frac{\int_{0}^{t} \dot{n}_{\mathrm{Ar}} x_{\mathrm{Ar}}^{-1}\left(x_{\mathrm{CO}_{2}}+x_{\mathrm{CO}}+x_{\mathrm{CH}_{4}}\right) \mathrm{d} t}{\int_{0}^{\infty} \dot{n}_{\mathrm{Ar}} x_{\mathrm{Ar}}^{-1}\left(x_{\mathrm{CO}_{2}}+x_{\mathrm{CO}}+x_{\mathrm{CH}_{4}}\right) \mathrm{d} t}
$$

The process parameters are listed in Table 1: furnace temperature, type of gasifying agent, partial pressure of gasifying agent, and type of feedstock. Carbon conversions are shown in Fig. 2 as a function of reaction time for the five different experimental runs. Samples at $X_{\mathrm{C}}=0$ (after pyrolysis), 0.3, 0.7, and 1 (ash) obtained in each of the five experiments are selected for the subsequent analysis.

\section{Computer Tomography}

3.1 CT Scans. Low- and high-resolution computer tomography techniques are employed in this study. Low-resolution tomographic scans of the samples are obtained by exposing them to an unfiltered X-ray beam generated by electrons incident on a wolfram target. The generator is operated at $40-50 \mathrm{keV}$ and a current of 0.2-0.3 mA. A Hamamatsu flat panel C7942 CA-02 protected by a paper filter is used to detect the transmitted X-rays. The samples are scanned at 1800 angles (projections). Each projection consists of an average over six scans at $1.2 \mathrm{~s}$ exposure time. The scans are performed for voxel sizes of $10 \mu \mathrm{m}$ (at $X_{\mathrm{C}}=0,0.3,0.7$ ) and $5 \mu \mathrm{m}\left(\right.$ at $\left.X_{\mathrm{C}}=1\right)$. The fields of view investigated are 11.2

Table 1 Process parameters for the five experimental runs

\begin{tabular}{lcccc}
\hline Case & $\begin{array}{c}T \\
(\mathrm{~K})\end{array}$ & $\begin{array}{c}\text { Gasifying } \\
\text { agent }\end{array}$ & $\begin{array}{c}p_{\text {ga }} \\
(\mathrm{bar})\end{array}$ & $\begin{array}{c}\text { Feedstock } \\
(\mathrm{mm})\end{array}$ \\
\hline Reference & 1273 & $\mathrm{H}_{2} \mathrm{O}$ & 0.8 & Granular, $d_{\mathrm{m}}=1$ \\
Powder & 1273 & $\mathrm{H}_{2} \mathrm{O}$ & 0.8 & Powder, $d_{\mathrm{m}}=0.5$ \\
$T$ & 1173 & $\mathrm{H}_{2} \mathrm{O}$ & 0.8 & Granular, $d_{\mathrm{m}}=1$ \\
Reduced $p_{\mathrm{H}_{2} \mathrm{O}}$ & 1273 & $\mathrm{H}_{2} \mathrm{O}$ & 0.4 & Granular, $d_{\mathrm{m}}=1$ \\
$\mathrm{CO}_{2}$ & 1273 & $\mathrm{CO}_{2}$ & 0.8 & Granular, $d_{\mathrm{m}}=1$ \\
\hline \hline
\end{tabular}

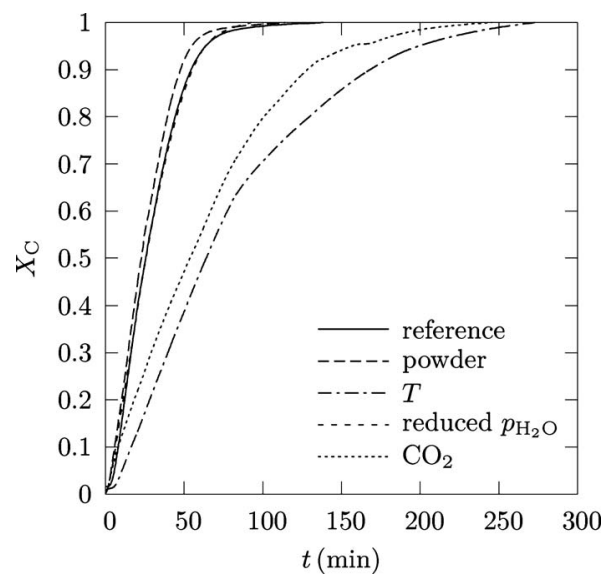

Fig. 2 Carbon extent $X_{\mathrm{C}}$ as a function of reaction time for five different sets of process parameters, as described in Table 1

$\times 11.2 \times 12 \mathrm{~mm}^{3}$ and $5.6 \times 5.6 \times 6 \mathrm{~mm}^{3}$, respectively. In addition, high-resolution tomography scans (voxel size of $0.37 \mu \mathrm{m}$ and field of view $0.76 \times 0.76 \times 0.62 \mathrm{~mm}^{3}$ ) are obtained with synchrotron radiation on the TOMCAT beamline at the Swiss Light Source (SLS) [24]. The scans are obtained for $10 \mathrm{keV}$ photon energy, $0.4 \mathrm{~mA}$ beam current, $100 \mu \mathrm{m}$ thick Al filter, 20 times geometrical magnification, $1.5 \mathrm{~s}$ exposure time, and 1501 projections. Figure 3 shows tomograms obtained with the low-resolution scans for the reference case sample at $X_{\mathrm{C}}=0,0.3,0.7$, and 1 (Fig. $3(a))$ and with the high-resolution scans for a single particle of the reference case sample at $X_{\mathrm{C}}=0.3$ (Fig. 3(b)). The latter scan was performed to examine the amount of pores below $5 \mu \mathrm{m}$.

3.2 Image Processing and Digitalization. The data obtained by tomography consist of 2 byte (0-65535) optical density values, $\alpha(\mathbf{x})$, arranged on a 3D Cartesian grid. The data is digitally improved by brightness and contrast adjustment, and by intensity transformation, obtained via a two-step gamma correction:

$$
f_{\gamma}(\alpha)= \begin{cases}\left(c^{\gamma_{1}-1} \alpha\right)^{1 / \gamma_{1}} & \text { for } \alpha<\mathrm{c} \\ \left(\frac{\left(2^{b}-1\right)^{\gamma_{2}}-c^{\gamma_{2}}}{\left(2^{b}-1\right)-c}(\alpha-c)+c^{\gamma_{2}}\right)^{1 / \gamma_{2}} & \text { for } \alpha \geq \mathrm{c}\end{cases}
$$

where $b$ is the number of bits of the image (16), $\gamma_{1}$ and $\gamma_{2}$ are the gamma correction factors, and $c$ denotes the absorption value where the two transformations interchange. For example, for $X_{\mathrm{C}}$ $=0, c=0.4\left(2^{b}-1\right)$. When appropriate, median filtering is applied to reduce the noise.

The detailed mathematical methodology to obtain the continuous representation of the optical density values is described in detail elsewhere [9]. A short summary is given here. The discrete values obtained by CT and subsequent image processing are linearly interpolated in three dimensions. The iso-surface describing the phase interface is obtained when the continuous density value equals the threshold value for phase segmentation $\alpha_{0}(\mathbf{x})$. Due to the highly heterogeneous material containing optically thin carbon-containing compounds and optically thick heavy metal impurities, phase segmentation is complicated. Local multistep threshold segmentation, implemented in MATLAB, is used to allow for more accurate phase detection. A representative rendered 3D geometry is shown in Fig. 4. The pore-space indicator function $\psi(\mathbf{x})$ is defined as

$$
\psi(\mathbf{x})= \begin{cases}1 & \text { if } \alpha(\mathbf{x}) \geq \alpha_{0}(\mathbf{x}) \\ 0 & \text { if } \alpha(\mathbf{x})<\alpha_{0}(\mathbf{x})\end{cases}
$$

The distance of a random point in the sample to the phase boundary is found by following a generic ray in small steps (searching for the root). Afterward, the bisection method is used to find the 
(a)

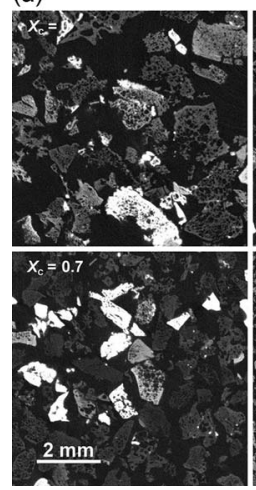

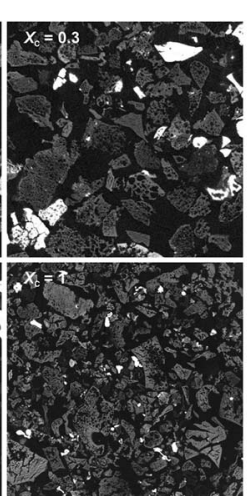

(b)

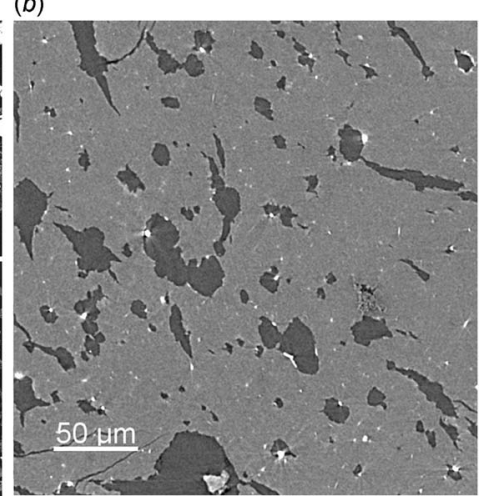

Fig. 3 Tomograms of the reference case sample for: (a) scans (voxel size $=10$ and $5 \mu \mathrm{m})$ at $X_{C}=0,0.3,0.7$, and 1 , and $(b)$ submicron scans (voxel size $=0.37 \mu \mathrm{m})$ of a particle at $X_{\mathrm{C}}=0.3$

exact value. The normal unit vector at the interface is determined by computing the gradient of the gray values at the specific position.

\section{Morphological Characterization}

4.1 Experimental. Porosity is determined by weight measurements, assuming the approximate intrinsic density to increase linearly with decreasing carbon content, and is given by $\rho$ $=\rho_{\text {ash }} X_{\mathrm{C}}+\rho_{\mathrm{C}}\left(1-X_{\mathrm{C}}\right) \quad$ with $\rho_{\mathrm{C}}=1700 \mathrm{~kg} \mathrm{~m}^{-3}$ and $\rho_{\text {ash }}$ $=2500 \mathrm{~kg} \mathrm{~m}^{-3} \cdot \rho_{\text {tire }}$ of the initial tire shreds (before pyrolysis) is measured by He pycnometry (AccuPyc 1330) to be $1200 \mathrm{~kg} \mathrm{~m}^{-3}$. $\varepsilon$ is shown in Fig. 5 as a function of the carbon conversion for the five experimental runs listed in Table 1 . The porosity peaks at $X_{\mathrm{C}}=0.55$ as a result of growing pores and break-up of fragile particles [25]. The measured values correspond to a loosely packed-bed of randomly oriented and located non-spherical particles having uniform size and sphericity (fraction of surface area of volume-equivalent sphere to surface area of particle) smaller than 0.25 [26], indicating highly porous particles. The measured porosity is fitted to a second order polynomial function (RMS $=0.04)$.

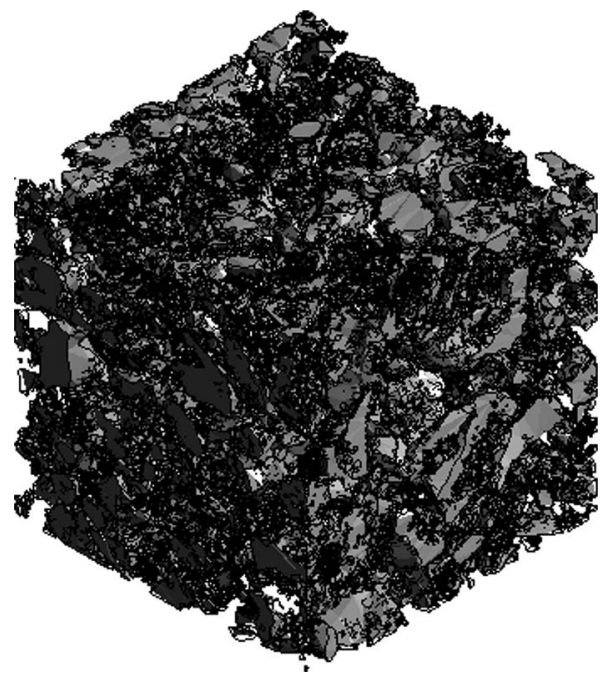

Fig. 4 A 3D rendered geometry of the reference case at $X_{\mathrm{C}}$ $=0$ with cube length of $1.5 \mathrm{~cm}$

$$
\varepsilon_{\mathrm{ex}}\left(X_{\mathrm{C}}\right)=-0.243 X_{\mathrm{C}}^{2}+0.269 X_{\mathrm{C}}+0.856
$$

The porosity of the unreacted packed-bed of tire shreds is determined to be $\varepsilon_{\text {ex }}=0.60 \pm 0.05$, which corresponds to a packed-bed of non-spherical particles of uniform size and with sphericity of $0.55[26]$.

The BET specific surface area and the corresponding fraction resulting from nanopores $\left(d_{\mathrm{p}}<2 \mathrm{~nm}\right)$ is shown Fig. 6 as a function of the carbon conversion for the five experimental runs listed in Table 1. Before pyrolysis, BET surface area is $0.6 \mathrm{~m}^{2} \mathrm{~g}^{-1}$ for the granular and $1.6 \mathrm{~m}^{2} \mathrm{~g}^{-1}$ for the powder feedstock, and no nanopores are detected. During pyrolysis, it increases to $70 \mathrm{~m}^{2} \mathrm{~g}^{-1}$ of which a small fraction $(\sim 5 \%)$ is associated to nanopores. During gasification, the BET specific surface area increases up to $\sim 700 \mathrm{~m}^{2} \mathrm{~g}^{-1}$ for $X_{\mathrm{C}}=0.7$ and decreases for the residual ash $\left(X_{C}=1\right)$, which is consistent with the variation in porosity in Fig. 5. The fraction of nanopores increases and peaks at $60 \%$ for $X_{\mathrm{C}}$ $=0.3$. No nanopores are detected in the ash. The different values obtained for $\mathrm{H}_{2} \mathrm{O}$ and $\mathrm{CO}_{2}$ gasifying agents are presumable the result of different mechanisms as $\mathrm{CO}_{2}$ mainly reacts at the external surface while $\mathrm{H}_{2} \mathrm{O}$ diffuses to the particle core [27]. In general, the variation in the reaction temperature, partial pressure, gasifying agent, and particle-size (as described in Table 1) do not significantly affect the morphology of the sample at the same

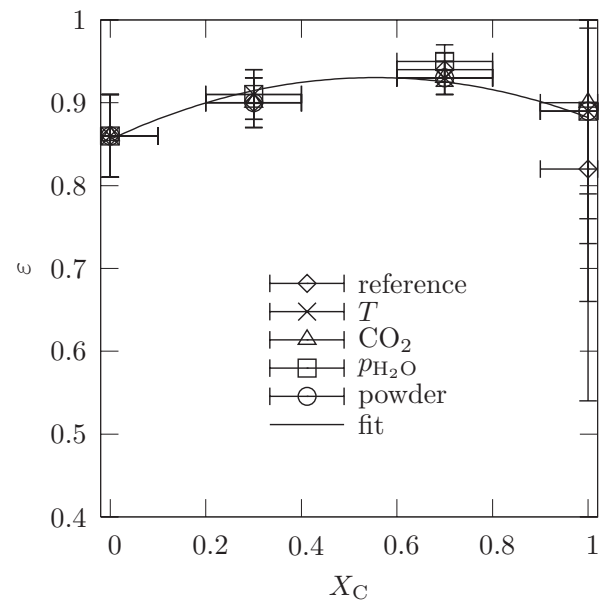

Fig. 5 Experimentally determined porosity for the packed-bed of tire shred as a function of carbon conversion for the five experimental runs listed in Table 1 


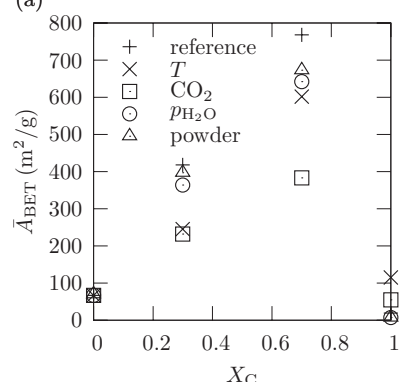

(b)

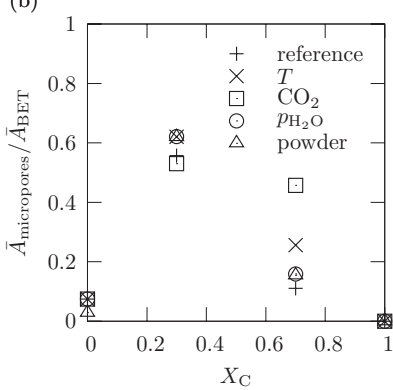

Fig. 6 Experimentally determined specific surface area (a) and the corresponding fraction resulting from micropores $(b)$ as a function of carbon conversion for the five experimental runs listed in Table 1

carbon conversion.

The experimentally measured particle-size distribution is shown in Fig. 7 for the reference case at $X_{\mathrm{C}}=0,0.3,0.7,1$. As expected, the main peak shifts to the left as particles shrink, and the small peaks-associated with smaller particles resulting from particle break-up-increase during the reaction. Note that these distributions are qualitative as particles are not spherical.

4.2 Numerical. The two-point correlation function

$$
s_{2}(r)=\frac{\int_{V} \int_{4 \pi} \psi(\mathbf{r}) \psi(\mathbf{r}+r \hat{\mathbf{s}}) \mathrm{d} \Omega \mathrm{d} V}{4 \pi V}
$$

is applied to calculate the porosity and specific surface area of the sample since $s_{2}(0)=\varepsilon$ and $\mathrm{d} s /\left.\mathrm{d} r\right|_{r=0}=-A_{0} / 4$ [1]. The particle-size distribution is calculated by an opening; a morphology operation consisting of an erosion followed by a dilation with the same structuring element [28]. A sphere is used as the structuring element. The determined opening porosity is related to the size distribution by

$$
f(d)=\frac{\mathrm{d}}{\mathrm{d} d}\left(1-\frac{\varepsilon_{\mathrm{op}}}{\varepsilon_{0}}\right)
$$

The calculated porosity of the unreacted packed-bed of 0.61 compares well to the experimentally determined one of $0.60 \pm 0.05$. Figure 8 shows the experimentally measured and numerically calculated porosity as a function of the carbon conversion during gasification for the reference case. The failure in predicting the porosity and its increase with increasing $X_{\mathrm{C}}$ is related to the res-

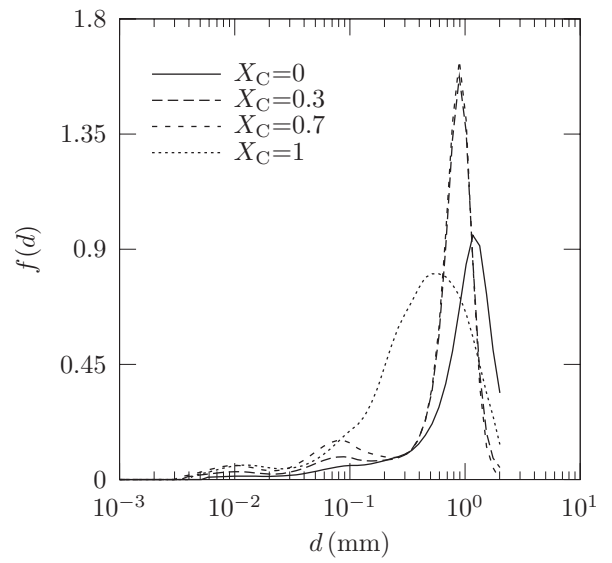

Fig. 7 Experimentally measured size distribution of the particles for the reference case at various carbon conversions $X_{\mathrm{C}}=0,0.3,0.7,1$

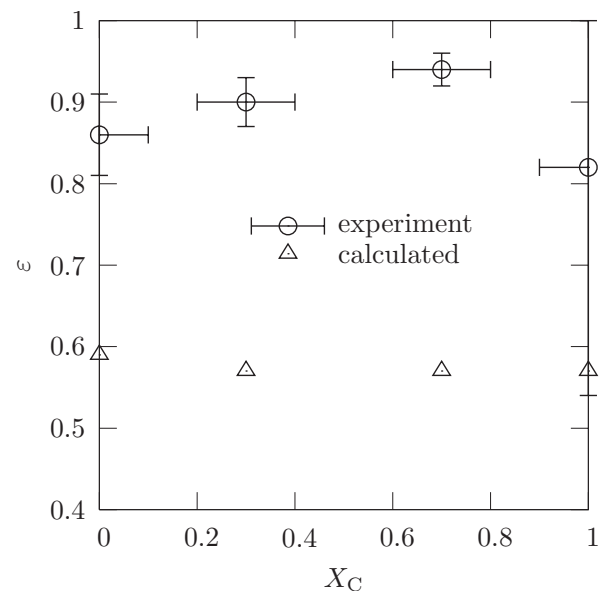

Fig. 8 Experimentally measured and numerically calculated porosity as a function of the carbon conversion for the reference case

olution of the tomographic scans, which is limited by the tomographic setup, the subsequent image processing (especially filtering) and the relative increase in optically thick material, which distorts the tomographic image. The impact of the insufficient scanning resolution and subsequent image processing is roughly calculated to be $(1-\varepsilon) \varepsilon_{\text {sub }} \approx 0.1$, where $\varepsilon_{\text {sub }}\left(\approx 0.2\right.$ for $\left.X_{\mathrm{C}}=0.3\right)$ is the porosity of the particle only detectable by the high-resolution tomography. Nanopores are not detectable but obviously present as indicated by the BET measurements. Calculated specific surface shows an increase up to $X_{\mathrm{C}}=0.7$ but the experimentally observed decrease for the ash is not elucidated.

The numerically calculated particle-size distributions, shown in Fig. 9 for the reference case at $X_{\mathrm{C}}=0,0.3,0.7,1$, are based on the largest sphere that fits inside the particle. Therefore, for nonspherical, complex, porous and fractal-like particles, these distributions deviate from those experimentally measured. The calculations are limited by the voxel size of the CT scans $\left(d_{\text {min }}\right.$ $=4 \cdot$ voxel size). Since the particle-size distribution is calculated based on the solid phase, the limited resolution of the CT scans leads to an over prediction of the particle-size due to virtual particle agglomeration. The measurements show (see Fig. 7) that the amount of particles in the $10 \mu \mathrm{m}$ range is small compared with that in the $100 \mu \mathrm{m}$ range. Therefore the influence of this distortion is assumed negligible on the particle-size distribution in the

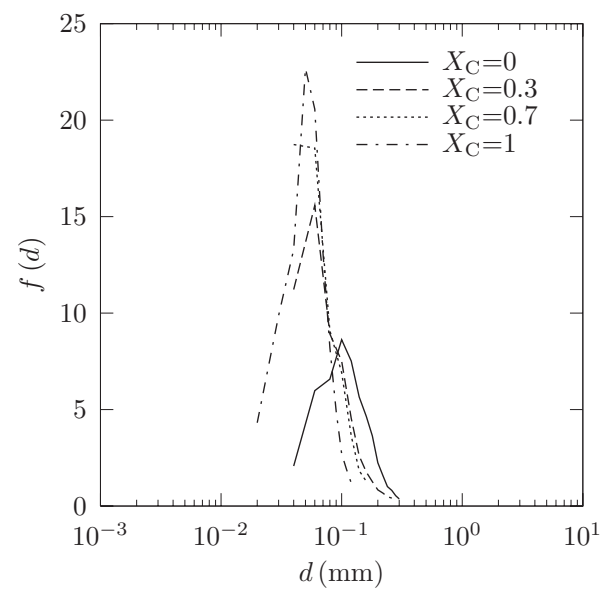

Fig. 9 Numerically calculated particle-size distribution for the reference case at various carbon conversions $X_{C}=0,0.3,0.7,1$ 
range of $60-100 \mu \mathrm{m}$. Indeed, an increase in small particles due to shrinkage and breakup of the initial ones during the reaction is observed.

The representative elementary volume (REV) - the smallest volume that can be considered as continuum-is determined by calculating the porosity of a subsequently growing subsample until its variation is within a tolerance band of \pm 0.05 [3]. The edge length of the REV, $l_{\mathrm{REV}}$, was found to be equal to $5 \mathrm{~mm}$, independent of the process parameters.

\section{Radiative Heat Transfer Characterization}

The packed-bed of the carbonaceous material is assumed to be opaque for visible and near-infrared radiation, which is the spectral range encountered in the solar-driven reactor [23]. The fluid phase is assumed to be radiatively non-participating. Hence, the variation in the radiative intensity in continuum models is described by a single equation of radiative transfer (RTE) [29,30].

$$
\frac{\mathrm{d} I_{\lambda}(s, \hat{\mathbf{s}})}{\mathrm{d} s}+\beta_{\lambda} I_{\lambda}(s, \hat{\mathbf{s}})=\kappa_{\lambda} I_{\lambda, \mathrm{b}}(s, \hat{\mathbf{s}})+\frac{\sigma_{\mathrm{s}, \lambda}}{4 \pi} \int_{4 \pi} I_{\lambda}\left(s, \hat{\mathbf{s}}_{\mathrm{in}}\right) \Phi_{\lambda}\left(\hat{\mathbf{s}}, \hat{\mathbf{s}}_{\mathrm{in}}\right) \mathrm{d} \Omega_{\mathrm{in}}
$$

Since the smallest pores or particles detected by CT and consequently employed in the analysis are larger than the voxel sizes of the low-resolution scans, geometric optics can be assumed for radiation wavelengths smaller than $1 \mu \mathrm{m}$ [17]. Collision-based Monte Carlo (MC) method is applied to compute the cumulative distribution functions of the radiation mean free path $G_{\mathrm{e}}(s)$ and of the cosine of incidence at the solid wall $F_{\mu_{\text {in }}}\left(\mu_{\text {in }}\right)$ defined as

$$
\begin{aligned}
& G_{\mathrm{e}}(s)=\int_{0}^{s} \frac{1}{N_{\mathrm{r}}} \sum_{j=1}^{N_{\mathrm{r}}} \delta\left(s^{\prime}-s_{j}^{\prime}\right) d s^{\prime} \\
& F_{\mu_{\text {in }}}\left(\mu_{\mathrm{in}}\right)=\frac{1}{N_{\mathrm{e}}} \sum_{j=1}^{N_{\mathrm{e}}} \delta\left(\mu_{\text {in }}-\mu_{\mathrm{in}, j}\right)
\end{aligned}
$$

$G_{\mathrm{e}}(s)$ and $F_{\mu_{\text {in }}}\left(\mu_{\text {in }}\right)$ are related to $\beta_{\lambda}$ and $\Phi_{\lambda}[2,5,8]$ by

$$
\Phi\left(\mu_{\mathrm{s}}\right)=\frac{2 \int_{\mu_{\mathrm{in}=0}}^{1} \int_{\varphi_{\mathrm{d}}=0}^{\pi} \int_{\mu_{\mathrm{r}}=0}^{1} \delta\left(\mu_{\mathrm{s}}-\sqrt{\left(1-\mu_{\mathrm{e}}^{2}\right)\left(1-\mu_{\mathrm{r}}^{2}\right)} \cos \varphi_{\mathrm{d}}-\mu_{\mathrm{in}} \mu_{\mathrm{r}}\right) \rho^{\prime \prime}\left(\mu_{\mathrm{in}}, \mu_{\mathrm{r}}, \varphi_{d}\right) F_{\mu_{\mathrm{in}}} \mu_{\mathrm{r}} d \mu_{\mathrm{r}} d \varphi_{\mathrm{d}} d \mu_{\mathrm{in}}}{\int_{\mu_{\mathrm{in}}=0}^{1} \int_{\varphi_{\mathrm{d}}=0}^{\pi} \int_{\mu_{\mathrm{r}}=0}^{1} \rho^{\prime \prime}\left(\mu_{\mathrm{in}}, \mu_{\mathrm{r}}, \varphi_{\mathrm{d}}\right) F_{\mu_{\mathrm{in}}} \mu_{\mathrm{r}} d \mu_{\mathrm{r}} d \varphi_{\mathrm{d}} d \mu_{\mathrm{in}}}
$$

The absorption characteristics of the samples and the contribution of dependent scattering vary with the reaction extent since ash is less absorbing than coal $\left(\rho_{\mathrm{r}, \mathrm{sp}, \mathrm{C}}=0.273, \rho_{\mathrm{r}, \mathrm{d}, \mathrm{C}}=0.1, \quad \rho_{\mathrm{r}, \mathrm{sp}, \text { ash }}\right.$ $=0.092$, and $\left.\rho_{\mathrm{r}, \mathrm{d}, \mathrm{ash}}=0.75[31,32]\right)$. Gas, packed-sphere, liquid, and modified liquid models are used to estimate the corresponding deviations of the scattering and absorption coefficients from the corresponding values obtained by assuming independent scattering [33]. For a packed-bed with $d_{\mathrm{m}}=0.4$ and $1 \mathrm{~mm}\left(d_{\mathrm{m}}\right.$ of particlesize distribution shown in Fig. 7 at $X_{\mathrm{C}}=1$ and 0 , respectively), the maximum deviation of the scattering efficiency (appearing at the largest radiation wavelength in our spectral range of interest $1 \mu \mathrm{m}$ ) is $5 \%$ and $23 \%$ for $\varepsilon_{\mathrm{ex}}=0.88$ and 0.86 , respectively, (mea-

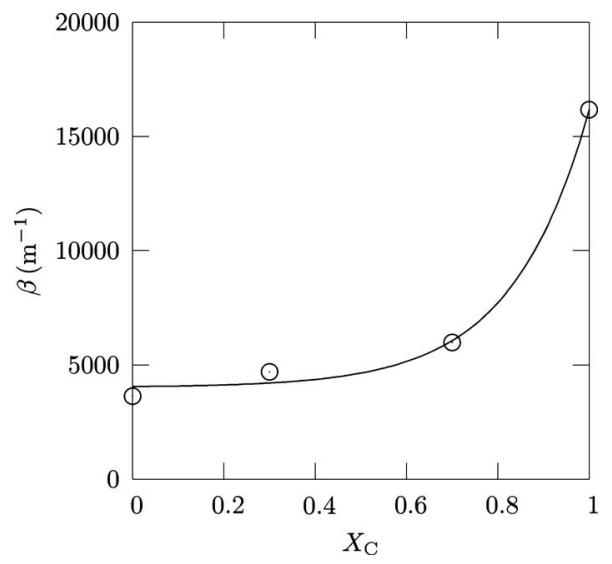

Fig. 10 Extinction coefficient as a function of carbon conversion (markers) and its fit (solid line) given by Eq. (11) sured and depicted in Fig. 5 at $X_{\mathrm{C}}=1$ and 0, respectively). Consequently, dependent scattering effects are neglected in the radiative transfer analysis.

The cumulative distribution function of the cosine of incidence at the solid wall and the scattering phase function are computed for two limiting cases: a specular and a diffuse solid-gas interface. For tire shreds, a combination of these two cases is anticipated to be valid. The specular directional-hemispherical reflectivity is calculated using Fresnel's equations for the complex refractive index of the carbon-ash mixture $m=\left(1-X_{\mathrm{C}}\right) m_{\mathrm{C}}+X_{\mathrm{C}} m_{\text {ash }}$, where $m_{\mathrm{C}}$

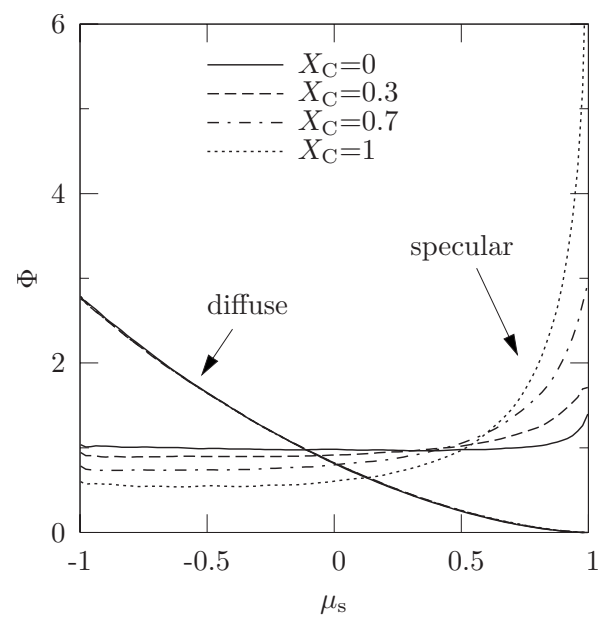

Fig. 11 Scattering phase function for the reference case at various carbon conversions $X_{C}=0,0.3,0.7,1$ for diffusely and specularly reflecting particles 
Table 2 Coefficients of the exponential fit to the scattering phase function for specularly reflecting solid-gas interface as a function of $X_{\mathrm{C}}$

\begin{tabular}{lcccc}
\hline \hline$X_{\mathrm{C}}$ & $A$ & $b$ & $c$ & RMS \\
\hline 0 & 0.986 & $5.031 \times 10^{-7}$ & 13.55 & 0.017 \\
0.3 & 0.899 & $1.415 \times 10^{-2}$ & 4.057 & 0.001 \\
0.7 & 0.750 & $3.622 \times 10^{-2}$ & 4.017 & 0.009 \\
1 & 0.614 & $6.377 \times 10^{-3}$ & 6.697 & 0.124 \\
\hline \hline
\end{tabular}

$=2.2-1.12 i$ is the complex refractive index of carbon and $m_{\text {ash }}$ $=1.5-0.02 i$ is the complex refractive index of ash $[17,34]$. Note that the cumulative distribution function of radiation mean free path, and consequently, the extinction coefficient are independent of the interface reflection type in the geometrical optics range.

The extinction coefficient $\beta$ and scattering phase function $\Phi$ are shown in Figs. 10 and 11, respectively, for the reference case at $X_{\mathrm{C}}=0,0.3,0.7,1 . \beta$ increases with $X_{\mathrm{C}}$ as particles shrink and shorten the attenuation path length. An empirical correlation of the extinction coefficient inversely proportional to the characteristic diameter supports this trend [18]. The extinction coefficient is fitted to an exponential function (RMS / $\beta_{X_{C}=0}=0.09$ ):

$$
\beta_{\mathrm{MC}}\left(X_{\mathrm{C}}\right)=4024+32.14 \exp \left(5.93 X_{\mathrm{C}}\right)
$$

The scattering phase function is independent of the reaction extent for the assumed diffusely reflecting interface. This result is consistent with the small differences obtained between the phase functions for diffuse reflecting identical overlapping transparent spheres and for diffuse reflecting identical overlapping opaque spheres $[3,6,9]$, although largely differing in morphology. $\Phi$ is described by a second order polynomial function $(\mathrm{RMS}=0.01)$.

$$
\Phi_{\mathrm{d}}=0.565 \mu_{\mathrm{s}}^{2}-1.394 \mu_{\mathrm{s}}+0.812
$$

In contrast, the scattering phase function for specularly reflecting particles exhibits a large forward scattering peak. This peak is enhanced with increasing $X_{\mathrm{C}}$ due to the decrease in the real part of the refractive index of the carbon-ash particle. The coefficients of the exponential fit, described by Eq. (14), are listed in Table 2.

$$
\Phi_{\mathrm{sp}}=a+b \exp \left(c \mu_{\mathrm{s}}\right)
$$

The scattering albedo $\left(\sigma_{\mathrm{s}} / \beta\right)$ can be approximately calculated as

$$
\frac{\sigma_{\mathrm{s}}}{\beta}=\left(1-X_{\mathrm{C}}\right) \rho_{\mathrm{r}, \mathrm{C}}+X_{\mathrm{C}} \rho_{\mathrm{r}, \mathrm{ash}}
$$

For the specular solid-gas interface, $\sigma_{\mathrm{s}} / \beta=0.273$ and 0.092 at $X_{\mathrm{C}}=0$ and 1 , respectively. For the diffuse solid-gas interface $\sigma_{\mathrm{s}} / \beta=0.1$ and 0.75 , respectively, $[31,32]$.

\section{Conclusions}

CT-based computational techniques were used to characterize the morphology (porosity, specific surface, particle-size distribution, and the REV for continuum domain) and the effective radiative heat transfer properties (extinction coefficient, scattering phase function, albedo) of a packed-bed undergoing a thermochemical reaction. The study was performed for the gasification of carbonaceous waste materials (tire shreds) to produce high-quality syngas. The variation in the morphology of the packed-bed was investigated at discrete carbon conversion steps $\left(X_{\mathrm{C}}=0,0.3,0.7\right.$, and 1) and for different process parameters (feedstock size, furnace temperature, gasifying agent, and partial pressure of gasifying agent). The CT scans were digitally improved to allow for more accurate phase segmentation. Numerical calculated and experimentally measured porosity (by weight), BET surface (by $\mathrm{N}_{2}$-adsorption), and particle-size distribution (by laser scattering) were compared. Discrepancies were due to limitations in the CT scan resolutions and to image distortions around optically thick heavy metal impurities. The morphological results can be used for the determination of structural parameters [25] needed in kinetic models. The extinction coefficient increased as particles shrank and shortened the attenuation path length. For diffuse reflecting particles, the scattering phase function was found to be independent of the reaction extent. For specularly reflecting particles, the scattering phase function exhibited a strong forward peak and dependency on the refractive index and therefore $X_{\mathrm{C}}$.

Further studies are directed to the determination of the effective properties for conduction heat transfer (thermal conductivity), convection heat transfer (interfacial heat transfer coefficient), and for fluid flow (permeability and Dupuit-Forchheimer coefficient).

\section{Acknowledgment}

This work has been financially supported by the Swiss National Science Foundation under Contract No. 200021-115888 and by the European Commission under Contract No. 212470 (Project HYCYCLES). We thank J. Gaabab for the technical support with the gasification experimental runs and F. Marone for the technical support at SLS.

\section{Nomenclature}

$$
\begin{aligned}
A_{0} & =\text { specific surface, } \mathrm{m}^{-1} \\
b & =\text { bit number of image } \\
c & =\text { constant, indicating gamma correction regime } \\
& \text { change } \\
d & =\text { particle diameter, } \mathrm{m} \\
F & =\text { probability density function } \\
f & =\text { size distribution function, } \mathrm{m}^{-1} \\
f_{\gamma} & =\text { two-step gamma correction function } \\
G_{\mathrm{e}} & =\text { cumulative distribution function of extinction } \\
I & =\text { length } \\
m & =\text { complative intensity, } \mathrm{W} \mathrm{m}^{-3} \mathrm{sr}^{-1} \\
N_{\mathrm{r}} & =\text { number of rays } \\
N_{\mathrm{e}} & =\text { number of extincted rays } \\
n & =\text { number of moles } \\
\dot{n} & =\text { molar flow rate } \\
p & =\text { (partial) pressure, bar } \\
r & =\text { distance between two points in the sample, } \mathrm{m} \\
\mathbf{r} & =\text { position vector for spatial coordinates in the } \\
s & =\text { sample } \\
s_{2} & =\text { two-point correlation function } \\
\hat{\mathbf{s}} & =\text { unit vector of path direction } \\
T & =\text { temperature, } \mathrm{K} \\
t & =\text { time, } \mathrm{s} \\
V & =\text { total sample volume, } \mathrm{m}^{3} \\
X_{\mathrm{C}} & =\text { carbon conversion } \\
x & =\text { molar fraction } \\
\mathbf{x} & =\text { spatial location vector, } \mathrm{m} \\
&
\end{aligned}
$$

Greek

$$
\begin{aligned}
\alpha & =\text { density value of tomographic scans } \\
\alpha_{0} & =\text { threshold density value for phase segmentation } \\
\beta & =\text { extinction coefficient, } \mathrm{m}^{-1} \\
\delta & =\text { Dirac delta function } \\
\varepsilon & =\text { porosity } \\
\gamma_{i} & =\text { gamma constant } \\
\kappa & =\text { absorption coefficient, } \mathrm{m}^{-1} \\
\lambda & =\text { radiation wavelength, } \mathrm{m} \\
\mu & =\text { directional cosine } \\
\rho & =\text { intrinsic density, } \mathrm{kg} \mathrm{m}^{-3} \\
\rho_{\mathrm{r}} & =\text { hemispherical reflectance } \\
\sigma_{\mathrm{s}} & =\text { scattering coefficient, } \mathrm{m}^{-1} \\
\varphi_{\mathrm{d}} & =\text { difference between azimutal angle of incidence } \\
& \text { and reflection, rad } \\
\Phi & =\text { scattering phase function }
\end{aligned}
$$




$$
\begin{aligned}
\psi & =\text { pore-space indicator function } \\
\Omega & =\text { solid angle, sr }
\end{aligned}
$$

Subscripts

$$
\begin{aligned}
\mathrm{b} & =\text { blackbody } \\
\mathrm{C} & =\text { carbon } \\
\mathrm{d} & =\text { diffuse } \\
\mathrm{ex} & =\text { experimental } \\
\mathrm{ga} & =\text { gasifying agent } \\
\mathrm{in} & =\text { incidence } \\
\mathrm{m} & =\text { mean } \\
\mathrm{min} & =\text { minimal } \\
\mathrm{op} & =\text { opening } \\
\mathrm{r} & =\text { reflection } \\
\mathrm{s} & =\text { scattering } \\
\mathrm{sp} & =\text { specular } \\
\mathrm{sub} & =\text { submicron } \\
0 & =\text { initial }
\end{aligned}
$$

\section{References}

[1] Berryman, J., and Blair, S., 1986, "Use of Digital Image Analysis to Estimate Fluid Permeability of Porous Material: Application of Two-Point Correlation Functions," J. Appl. Phys., 60, pp. 1930-1938.

[2] Rintoul, M. D., Torquato, S., Yeong, C., Keane, D. T., Erramilli, S., Jun, Y. N. Dabbs, D. M., and Aksay, I. A., 1996, "Structure and Transport Properties of Porous Magnetic Gel via X-Ray Microtomography," Phys. Rev. E, 54, pp. 2663-2669.

[3] Haussener, S., Lipiński, W., Petrasch, J., Wyss, P., and Steinfeld, A., 2009, "Tomographic Characterization of a Semitransparent-Particle Packed Bed and Determination of its Thermal Radiative Properties," ASME J. Heat Transfer, 131, p. 072701.

[4] Petrasch, J., Wyss, P., Stämpfli, R., and Steinfeld, A., 2008, "TomographyBased Multiscale Analyses of the 3D Geometrical Morphology of Reticulated Porous Ceramics," J. Am. Ceram. Soc., 91, pp. 2659-2665.

[5] Haussener, S., Coray, P., Lipiński, W., Wyss, P., and Steinfeld, A., 2010, "Tomography-Based Heat and Mass Transfer Characterization of Reticulate Porous Ceramics for High-Temperature Processing," ASME J. Heat Transfer, 132, p. 023305.

[6] Tancrez, M., and Taine, J., 2004, "Direct Identification of Absorption and Scattering Coefficients and Phase Function of a Porous Medium by a Monte Carlo Technique," Int. J. Heat Mass Transfer, 47, pp. 373-383.

[7] Coquard, R., and Baillis, D., 2004, "Radiative Characteristics of Opaque Spherical Particle Beds: A New Method of Prediction," J. Thermophys. Heat Transfer, 18, pp. 178-186.

[8] Coquard, R., and Baillis, D., 2005, "Radiative Characteristics of Beds of Spheres Containing an Absorbing and Scattering Medium," J. Thermophys. Heat Transfer, 19, pp. 226-234.

[9] Petrasch, J., Wyss, P., and Steinfeld, A., 2007, "Tomography-Based Monte Carlo Determination of Radiative Properties of Reticulate Porous Ceramics," J. Quant. Spectrosc. Radiat. Transf., 105, pp. 180-197.

[10] Zeghondy, B., Iacona, E., and Taine, J., 2006, "Determination of the Anisotropic Radiative Properties of a Porous Material by Radiative Distribution Function Identification (RDFI)," Int. J. Heat Mass Transfer, 49, pp. 28102819.

[11] Logtenberg, S., and Dixon, A. G., 1998, "Computational Fluid Dynamics Studies of Fixed Bed Heat Transfer," Chem. Eng. Process., 37, pp. 7-21.

[12] Huai, X., Wang, W., and Li, Z., 2007, "Analysis of the Effective Thermal
Conductivity of Fractal Porous Media," Appl. Therm. Eng., 27, pp. 28152821.

[13] Krishnan, S., Murthy, J. Y., and Garimella, S. V., 2006, "Direct Simulation of Transport in Open-Cell Metal Foam," ASME J. Heat Transfer, 128, pp. 793799.

[14] Petrasch, J., Schrader, B., Wyss, P., and Steinfeld, A., 2008, "TomographyBased Determination of the Effective Thermal Conductivity of Fluid-Saturated Reticulate Porous Ceramics," ASME J. Heat Transfer, 130, p. 032602.

[15] Petrasch, J., Meier, F., Friess, H., and Steinfeld, A., 2008, "Tomography Based Determination of Permeability, Dupuit-Forchheimer Coefficient, and Interfacial Heat Transfer Coefficient in Reticulate Porous Ceramics," Int. J. Heat Fluid Flow, 29, pp. 315-326.

[16] Boomsma, K., Poulikakos, D., and Ventikos, Y., 2003, "Simulations of Flow Through Open Cell Metal Foams Using an Idealized Periodic Cell Structure,' Int. J. Heat Fluid Flow, 24, pp. 825-834.

[17] Modest, M., 2003, Radiative Heat Transfer, 2nd ed., Academic, San Diego, CA.

[18] Hendricks, T. J., and Howell, J. R., 1996, "Absorption/Scattering Coefficients and Scattering Phase Functions in Reticulated Porous Ceramics," ASME J. Heat Transfer, 118, pp. 79-87.

[19] Kaviany, M., 1995, Principles of Heat Transfer in Porous Media, SpringerVerlag, New York.

[20] Incropera, F., and DeWitt, D., 2002, Fundamentals of Heat and Mass Transfer, Wiley, New York.

[21] Dullien, F., 1979, Porous Media Fluid Transport and Pore Structure, Academic, New York.

[22] Macdonald, I. F., El-Sayed, M. S., Mow, K., and Dullien, F. A. L., 1979, "Flow Through Porous Media-The Ergun Equation Revisited," Ind. Eng. Chem. Fundam., 18, pp. 199-208.

[23] Piatkowski, N., Wieckert, C., and Steinfeld, A., 2009, "Experimental Investigation of a Packed-Bed Solar Reactor for the Steam-Gasification of Carbonaceous Feedstocks," Fuel Process. Technol., 90, pp. 360-366.

[24] Streun, A., Böge, A., Dehler, M., Gough, C., Joho, W., Korhonen, T., Lüdeke, A., Marchand, P., Muñoz, M., Pedrozzi, M., Rivkin, L., Schilcher, T., Schlott, V., Schulz, L., and Wrulich, A., 2001, "Commissioning of the Swiss Light Source," Proceedings of the 2001 Particle Accelerator Conference, P. Lucas, and S. Webber, eds., IEEE, Piscataway, NJ, pp. 224-226.

[25] Lu, G. Q., and Do, D. D., 1994, "Comparison of Structural Models for HighAsh Char Gasification," Carbon, 32, pp. 247-263.

[26] 2003, Handbook of Fluidization and Fluid-Particle Systems, W. C. Yang, ed., Marcel Dekker, New York.

[27] Czechowski, F., and Kidawa, H., 1991, "Reactivity and Susceptibility to Porosity Development of Coal Maceral Chars on Steam and Carbon Dioxide Gasification," Fuel Process. Technol., 29, pp. 57-73.

[28] Vogel, H., and Roth, H., 2001, "Quantitative Morphology and Network Representation of Soil Pore Structure,” Adv. Water Resour., 24, pp. 233-242.

[29] Lipiński, W., Petrasch, J., and Haussener, S., 2010, "Application of the Spatial Averaging Theorem to Radiative Heat Transfer in Two-Phase Media," J. Quant. Spectrosc. Radiat. Transf., 111, pp. 253-258.

[30] Gusarov, A. V., 2008, "Homogenization of Radiation Transfer in Two-Phase Media With Irregular Phase Boundaries," Phys. Rev. B, 77, p. 144201.

[31] Touloukian, Y., Powell, R., Ho, C., and Klemens, P., 1970, Thermophysical Properties of Matter, IFI/Plenum, New York.

[32] Jones, M. T., Sparks, R. S., and Valdes, P. J., 2007, "The Climatic Impact of Supervolcanic Ash Blankets," Clim. Dyn., 29, pp. 553-564.

[33] Tien, C. L., and Drolen, B. L., 1987, "Thermal Radiation in Particulate Media With Dependent and Independent Scattering," Annu. Rev. Numer. Fluid Mech. Heat Transfer, 1, pp. 1-32.

[34] Ruan, L. M., Qi, H., An, W., and Tan, H. P., 2007, "Inverse Radiation Problem for Determination of Optical Constants of Fly-Ash Particles," Int. J. Thermophys., 28, pp. 1322-1341. 